\title{
ANALISA KEKUATAN SAMBUNGAN LAS ARGON PADA STAINLESS STEEL 304 MENGGUNAKAN VARIASI KUAT ARUS
}

\author{
Imam Syafa'at ${ }^{* 1}$, Helmy Purwanto ${ }^{1}$, Muhammad Ilhammudin ${ }^{1}$ dan Rita Dwi Ratnani ${ }^{2}$ \\ ${ }^{1}$ Jurusan Teknik Mesin, Fakultas Teknik, Universitas Wahid Hasyim \\ ${ }^{2}$ Jurusan Teknik Kimia, Fakultas Teknik, Universitas Wahid Hasyim \\ Jl. Menoreh Tengah X/22, Semarang, Indonesia \\ *Email: imamsyafaat@unwahas.ac.id
}

\begin{abstract}
Abstrak
Pengelasan merupakan metode penyambungan yang umum digunakan dalam bidang konstruksi maupun aplikasi di industri. Tujuan dari penelitian ini adalah untuk mengetahui karakteristik sifat fisik dari pengamatan struktur makro, mikro serta karakteristik mekanik dari pengujian tarik. Parameter pengelasan perlu diketahui karena berpengaruh dengan sifat mekanik material setelah dilakukan pengelasan. Pada penelitian ini proses pengelasan yang digunakan adalah GTAW atau TIG dengan gas Argon. Penelitian ini menggunakan variasi arus 60 A, 70 A, 80 A. Berdasarkan hasil pengujian spesimen dengan arus 80 A memiliki tegangan tarik maksimal tertinggi $744,162 \mathrm{MPa}$. tegangan tarik terendah pada arus $70 \mathrm{~A}$ dengan nilai 598,435 MPa. Dan regangan tertinggi $82 \%$ pada arus 80 A Hubungan antara kekuatan tarik dan struktur mikro semakin besar butiran logam yang dihasilkan maka tegangan luluhnya semakin kecil. Karena panas yang dihasilkan tidak cukup membuat elektroda tungsten dan bahan tambahnya meleleh dengan baik.
\end{abstract}

Kata kunci: stainless steel, GTAW, kuat arus, kekuatan tarik.

\section{PENDAHULUAN}

Dalam industri, teknologi konstruksi merupakan salah satu teknologi yang memiliki andil dalam berbagai sarana dan prasarana kebutuhan manusia. Perkembanganya semakin pesat dan tidak bisa dipisahkan dari teknik pengelasan dalam merancang suatu produk. Metode pengelasan sangatlah mempengaruhi hasil las. Metode yang digunakan harus sesuai dengan kebutuhan konstruksi.

Salah satu metode pengelasan yang biasa digunakan dalam pengelasan baja tahan karat (stainless steel) adalah Gas Tungsten Arc Welding (GTAW). Pengelasan ini bisa diaplikasikan untuk material baja. Karakter baja tahan karat merupakan baja paduan tinggi, menjadikan kualitas sambungan lasnya menjadi getas karena terpengaruh panas dari proses pengelasan (Yunus, 2013).

Menurut Widyatmoko dkk (2017) yang meneliti tentang pengaruh arus pengelasan GTAW terhadap karakteristik sifat mekanis stainless steel 304 bahwa semakin tinggi dan optimal panas yang dihasilkan pada proses pengelasan maka akan semakin baik dala melelehkan bahan tambah dan elektroda tungsten dengan logam induk.

Menurut penelitan yang dilakukan Setiawan (2016), tentang pengaruh pengelasan GTAW stainless steel 304. Dimana tujuan penelitian tersebut untuk mengetahui prosentase komposisi kimia dengan hasil diketahui jenis baja tahan karat austenitic paduan $\mathrm{Fe}-\mathrm{Cr}-\mathrm{Ni}$ dengan kadar $\mathrm{Fe}=71,45 \%, \mathrm{Cr}=18,12 \%, \mathrm{Ni}=$ $8,49 \%, \mathrm{Mn}=0,914 \%$.

Penelitian ini bertujuan untuk mengetahui perbedaan karakteristik sifat fisik dan mekanik material stainless 304 setelah dilakukan pengelasan dengan variasi arus $60 \mathrm{~A}$, $70 \mathrm{~A}, 80 \mathrm{~A}$ dengan pengujian foto makro, uji struktur mikro dan Uji kekuatan tarik. Kajian ini diaplikasikan untuk rancang bangun pirolisator.

\section{METODE PENELITIAN}

Alat dan bahan yang digunakan pada penelitian adalah

- Mesin las TIG Lakoni Inverter Welding tipe HAWK TIG 200e.

- Alat perkakas dan meja bangku.

- Bahan stainless steel 304 tebal 1,2mm.

Prosedur dalam penelitian ini adalah Pemilihan bahan, bahan yang digunakan stainless steel 304. proses pengelasan dengan metode pengelasan GTAW atau TIG, pada Gambar 1 menunjukkan material setelah dilakukan pengelasan, pembuatan spesimen menggunakan standar ASTM E8/E8M-09 terlihat pada Gambar 2, foto makro, uji foto mikro dan kekuatan tarik 


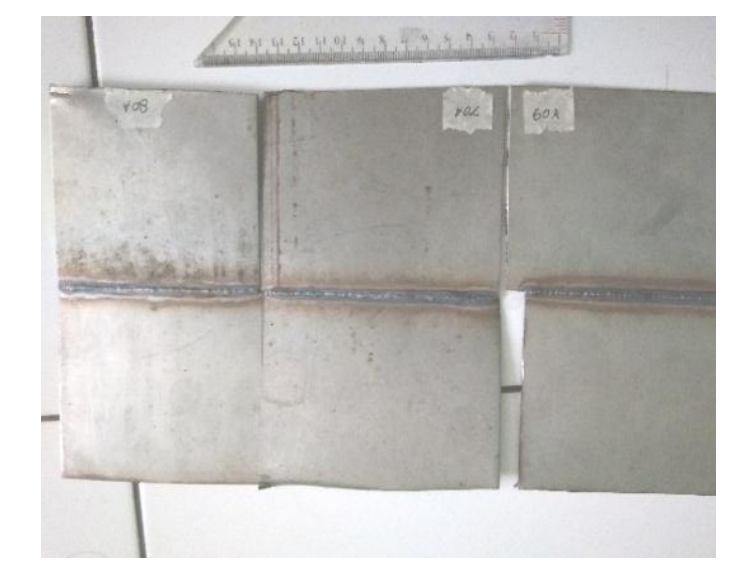

Gambar 1. Material yang dilas

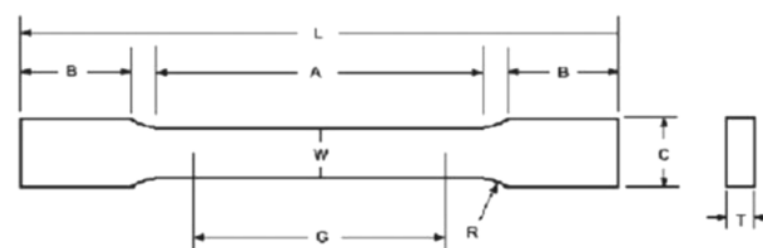

Gambar 2. Ukuran spesimen uji tarik ASTM E8

Keterangan:

$\mathrm{L}=100 \mathrm{~mm}$

$\mathrm{mm}$

$\mathrm{T}=1,2 \mathrm{~mm}$

$\mathrm{mm}$

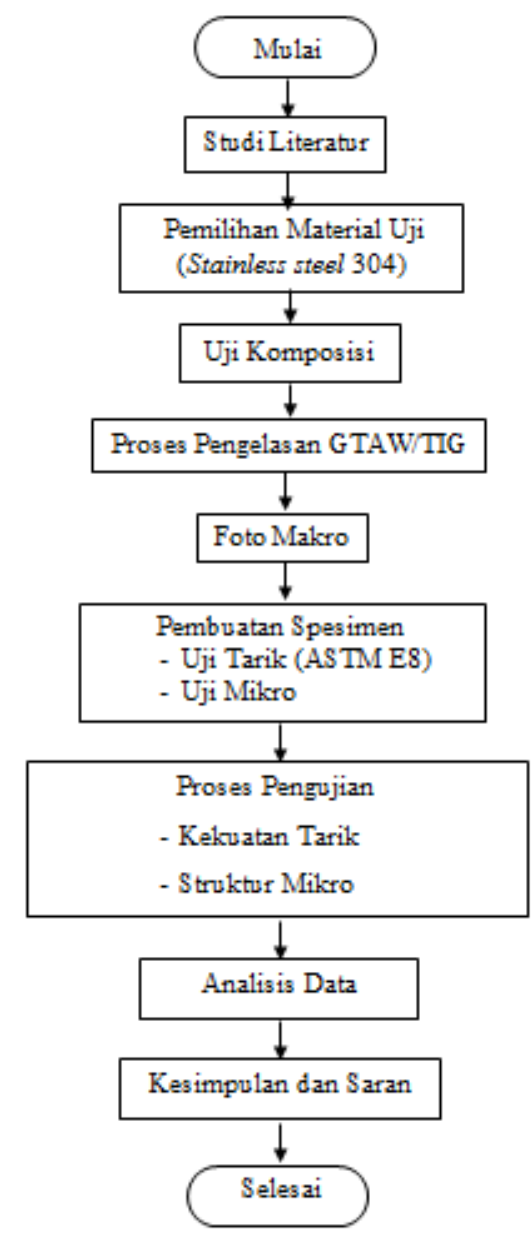

Gambar 3. Diagram alir

Gambar 3 merupakan alur atau langkahlangkah pada penelitian ini yang bertujuan untuk memudahkan peneliti dalam melakukan penelitian. Langkah pertama studi literatur, pemilihan material, uji komposisi, proses pengelasan, pembuatan spesimen, pengujian, dan seterusnya.

\section{HASIL DAN PEMBAHASAN}

Hasil Uji Komposisi Material

Hasil uji komposisi material seperti ditunjukkan dalam Tabel 1.

Tabel 1. Komposisi kimia stainless steel 304

\begin{tabular}{cccccccccc}
\hline Unsur & $\mathrm{Cr}$ & $\mathrm{Mn}$ & $\mathrm{Si}$ & $\mathrm{Fe}$ & $\mathrm{C}$ & $\mathrm{Ni}$ & $\mathrm{N}$ & $\mathrm{P}$ \\
& & & & & & & & \\
\hline$\%$ & 18,479 & 0,94 & 0,296 & 71,334 & 0,053 & 8,232 & 0,039 & 0,0401
\end{tabular}

Material ini memiliki kandungan karbon, dimana karbon mempunyai sifat dapat meningkatkan kekerasan dan kekuatan tetapi menurunkan kemampuan tempa dan keuletan. Kandungan kromnya memberikan pengaruh dalam proses kimia terutama pada saat proses 
pemanasan. Stainless steel dipilih sebagai material kerja karena sifat tahan panas pada temperatur tinggi dan ketahan terhadap korosi.

\section{Hasil Foto Makro}

Gambar 4 hasil pengelasan yang paling bagus adalah pada arus $80 \mathrm{~A}$. Hasil pengelasan pada arus $60 \mathrm{~A}$, dan $70 \mathrm{~A}$ bahan tambah tidak mencair dengan maksimal terlihat masih ada sekat-sekat pada daerah pengelasan. Semua perbedaan tersebut karena dipengaruhi besar kecilnya panas yang masuk dan juga kecepatan pengelasan. Foto Makro dapat dilihat pada Gambar 4
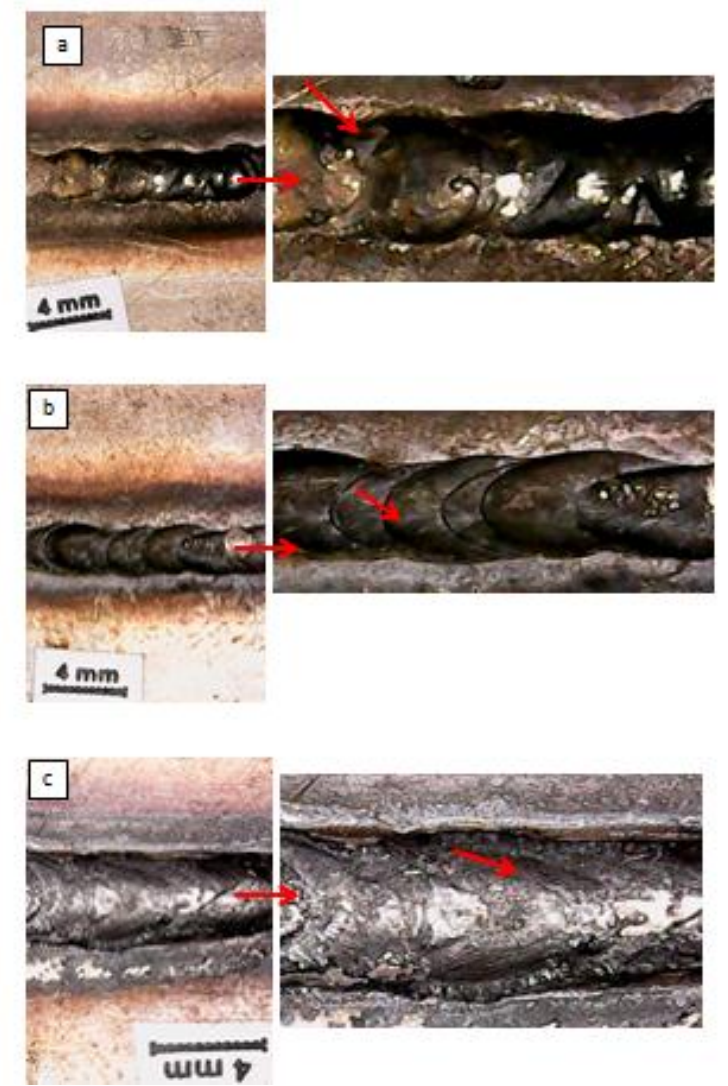

Gambar 4. Foto makro hasil pengelasan (a) Arus 60 A, (b) Arus 70 A, (c) Arus 80 A.

Gambar 5 merupakan pengamatan foto makro setelah proses etsa.

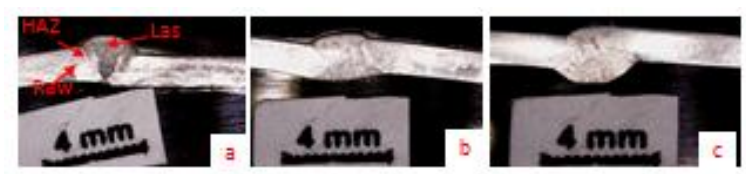

Gambar 5. Foto makro setelah etsa, (a) $60 \mathrm{~A}$, (b) $70 \mathrm{~A}$, (c) $80 \mathrm{~A}$

Sebelum dilakukan foto makro ini, bahan dipotong dan dihaluskan kemudian dilakukan proses etsa. Terlihat perbedaan pengelasan arus $60 \mathrm{~A}, 70 \mathrm{~A}, 80 \mathrm{~A}$. Bahwa pada pengelasan arus 60 A dan 70 A, logam bahan tambahnya tidak mampu mencair maksimal dengan logam induknya.

\section{Hasil Foto Mikro}

Pada gambar 6 hasil struktur mikro pada hasil uji metalografi menunjukkan tiga fasa yaitu fasa ferit (kelihatan gelap), dan austenite (terlihat lebih terang) fasa ini terlihat sedikit karena belum ada perlakuan sama sekali.

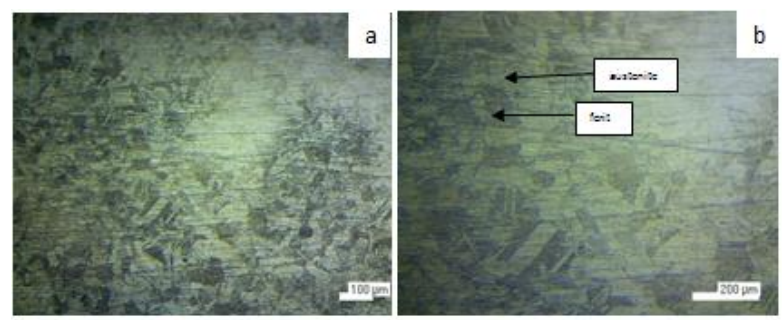

Gambar 6. Foto mikro logam induk (a) perbesaran 100x (b) perbesaran 200x

Pada Gambar 7 struktur mikro pada pengelasan arus $60 \mathrm{~A}$. Dimana struktur mikro antara daerah Heat Affected Zone (HAZ) dan las mempunyai fasa yang hampir sama. Adapun yang membedakannya adalah batas butirnya pada daerah logam induk dan daerah HAZ hampir sama yaitu berbutir memanjang.

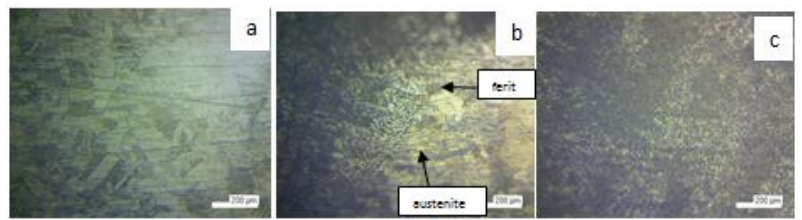

Gambar 7. Hasil struktur mikro (a) logam induk, (b) HAZ, (c) las

Pada Gambar 8 bahwa hasil pengelasan pada

arus $70 \mathrm{~A}$, dimana struktur mikro antara logam induk, HAZ, dan las mempunyai fasa ferit, austenite. Batas butir pada daerah HAZ dan logam induk hampir sama yaitu berbentuk oval atau kotak dengan bentuk pada daerah las berbutir memanjang.

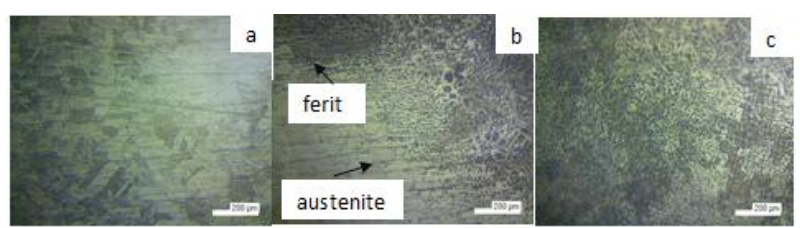

Gambar 8. Hasil struktur mikro, (a) logam induk, (b) HAZ, (c) las 
Gambar 9 pengelasan arus 80A dimana struktur mikro antara logam induk, HAZ, dan las mempunyai fasa yang hampir sama yaitu fasa austenite dan ferit. Bentuk batas butir pada daerah logam induk dan HAZ adalah berbutir memanjang

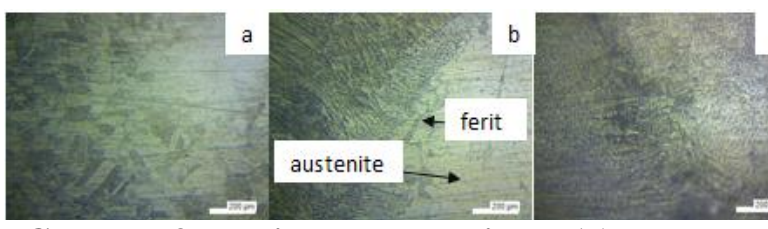

Gambar 9. Hasil struktur mikro, (a) logam induk, (b) HAZ, (c) las

Tabel 2. Perbandingan hasil struktur mikro

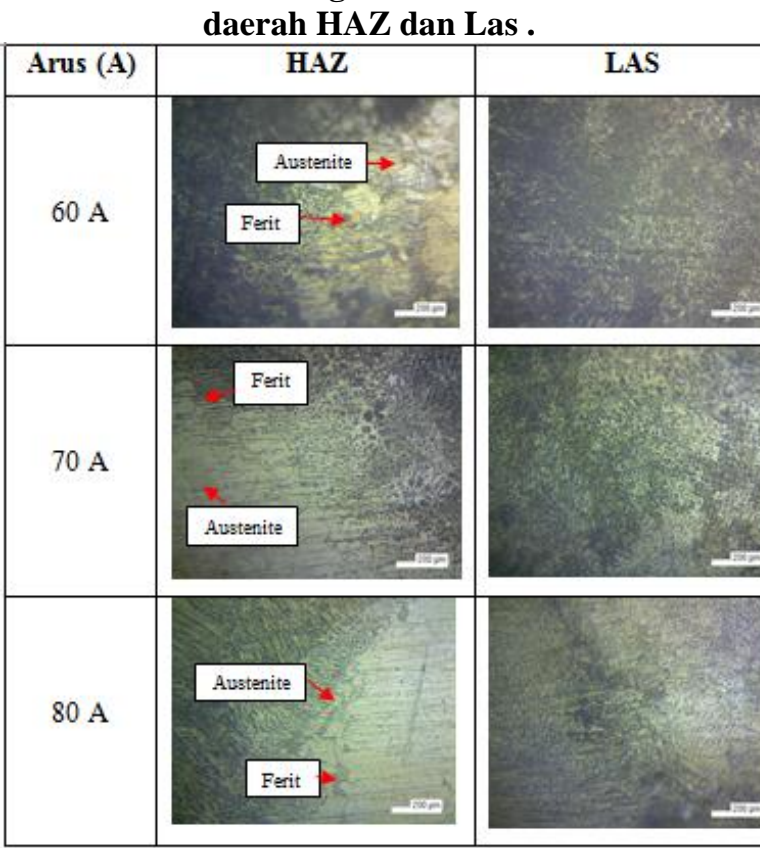

Pada tabel 2 menunjukkan perbedaan hasil struktur mikro daerah las dan HAZ, pada pengelasan $60 \mathrm{~A}, 70 \mathrm{~A}, 80 \mathrm{~A}$ memiliki struktur ferit halus dan struktur austenite kasar. Struktur yang terbentuk karena adanya transformasi panas (Callister, 2006). Perbedaan struktur pada daerah HAZ menunjukkan bahwa pada kuat arus 60 A lebih didominasi ferit, pada pengelasan arus $60 \mathrm{~A}$ panas yang masuk tidak terlalu besar sehingga untuk mencairkan material tambahnya kurang begitu baik nampak butiran pada daerah lasan, dengan demikian daerah pengaruh HAZ tidak terlalu luas (Saripudin, 2013).

Pada daerah las menunjukkan bahwa pengelasan kuat arus 60 A struktur yang dihasilkan terlihat lebih kasar dibanding pengelasan arus $70 \mathrm{~A}$ dan $80 \mathrm{~A}$. pada struktur mikro pengelasan $80 \mathrm{~A}$, ferit, austenite lebih halus dibanding pengelasan arus $70 \mathrm{~A}$. Menurut penelitian Widyatmoko dkk (2017) semakin besar panas yang masuk pada saat pengelasan maka butiran struktur mikronya semakin kasar yang mengakibatkan kekuatan pada daerah HAZ menjadi rendah.

\subsection{Pengujian Tarik}

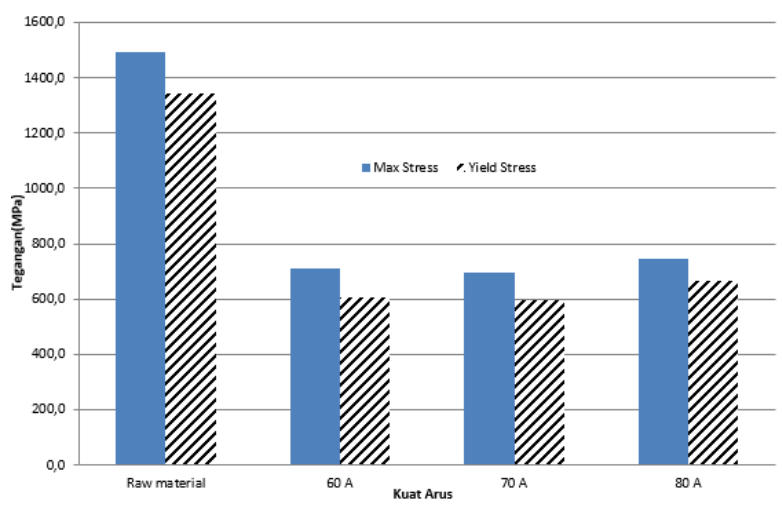

Gambar 10. Grafik hubungan antara tegangan tarik dengan kuat arus

Pada Gambar 10 menunjukkan bahwa hasil tegangan tarik paling tinggi $668,603 \mathrm{MPa}$ terletak pada pengelasan arus $80 \mathrm{~A}$, sedangkan nilai tegangan tarik terendah pada arus $70 \mathrm{~A}$ dengan nilai 598,435 $\mathrm{MPa}$. Tegangan tarik maksimal tertinggi pada pengelasan $80 \mathrm{~A}$ dengan nilai $744,162 \mathrm{MPa}$. Hal-hal yang mempengaruhi hasil pengujian menurut Widyatmoko dkk (2017) pada pengelasan TIG bahwa semakin tinggi panas yang dihasilkan pada pengelasan membuat kawat elektroda tungsten dan bahan tambahnya dapat meleleh dengan baik sehingga menjadikan las lebih kuat.

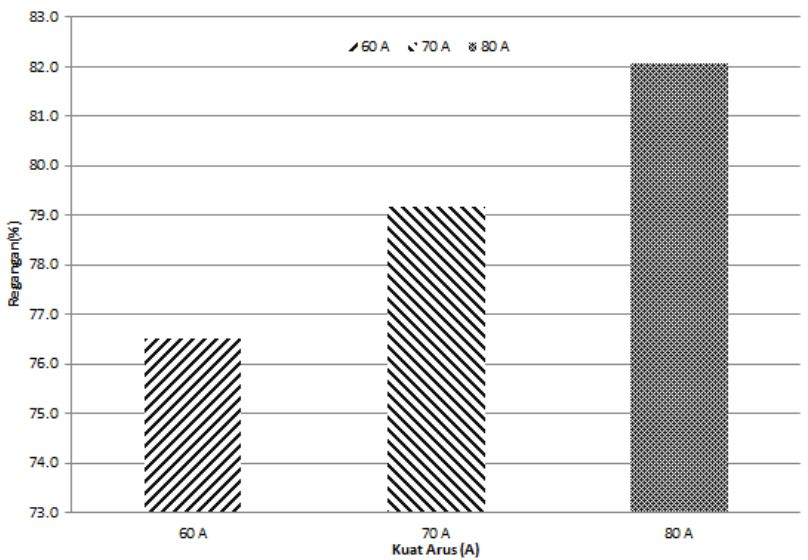

Gambar 11. Grafik hubungan kuat arus dengan regangan 
Pada gambar 11 grafik regangan menunjukkan hasil presentase perpanjangan bahan terletak pada arus 80 A dengan $82 \%$, sedangkan nilai terendah adalah $76,5 \%$ pada pengelasan 60 A. Menurut Suryanto dan Ilman (2016) hubungan antara struktur mikro dengan kekuatan tarik logam dimana semakin besar butiran logam yang dihasilkan maka kekuatan luluhnya semakin rendah. Dikarenakan panas yang dihasilkan kurang maksimal dan tidak cukup panas untuk melelehkan elektroda dan bahan tambahnya.

Dalam aplikasi, secara umum kekuatan sambungan las mampu menahan tekanan yang ada dalam pirolisator. Dalam kenyataannya, tabung penghasil uap cair ini tidaklah bersifat mampat dengan tekanan tertentu. Lubang output asap yang berhubungan udara luar membuat alat ini mempunyai tekanan sama dengan tekanan di luar tabung.

\section{KESIMPULAN}

1. Hasil foto makro yang paling bagus adalah pada pengelasan dengan kuat arus 80 A, sedangkan pengelasan pada kuat arus $60 \mathrm{~A}$ bahan tambahnya sulit meleleh karena arusnya terlalu kecil. Pada arus 60 A menghasilkan struktur mikro ferit, austenite dan karbida chromnya lebih kasar dan gelap. arus 70 A hasil struktur mikro ferit, austenite dan karbida chrom, lebih halus terang. Arus 80 A hasil struktur mikronya ferit, austenite, dan karbida chromnya lebih halus dari pengelasan kuat arus lainnya.

2. Hasil pengujian tarik yang paling tinggi 668,6 MPa terletak pada pengelasan $80 \mathrm{~A}$ karena struktur karbidanya lebih halus dan lebih banyak dibandingkan kuat arus lain. Sedangkan tegangan tarik dengan nilai terendah 598,4 $\mathrm{MPa}$ terletak pada pengelasan 70 A. tegangan tarik maksimum nilai tertinggi 744,1 $\mathrm{MPa}$ terletak pada pengelasan dengan kuat arus $80 \mathrm{~A}$.

\section{DAFTAR PUSTAKA}

Saripudin dan Mochammad Noer Ilman. (2013). Pengaruh Preheat terhadap Struktur Mikro dan Kekuatan Tarik Las Logam Tak Sejenis Baja Tahan Karat Austeniti AISI 304 dan Baja Karbon A36.Artikel Ilmiah.

Setiawan, A. (2016). Penelitian Stainless Steel 304 Terhadap Pengaruh Pengelasan GTAW Untuk Variasi Arus 50A, 100A Dan 160A Dengan Uji Komposisi, Struktur Mikro, Uji Kekerasan Dan Uji Impact. Universitas Muhammadiyah Surakarta.

Suryanto, Heru., Nasrul, Y., Qolik, A. Pengaruh Variasi Arus Las SMAW Terhadap Kekerasan dan Kekuatan Tarik Sambungan Dissimilar Stainless Steel 304 dan ST 37. Malang: Universitas Negeri Malang.

William D. Callister,Jr., (1990)., Materials Science And Engineering An Introduction., Second Edition., New York.

Widyatmoko, A., Muh Amin., Solechan. (2017). Pengaruh Arus Pengelasan Las TIG Terhadap Karakteristik Sifat Mekanis Stainless Steel Type 304. Semarang: Universitas Muhammadiyah Semarang.

Yunus dan Nofri, (2013). Variasi Arus Listrik Terhadap Sifat Mekanik Mikro Sambungan Las Baja Tahan Karat AISI 304. Volume 1, Nomor 1, E-journal Widya Eksakta. 